\title{
Alteration of transfer ribonucleic acid of Neisseria meningitidis during growth in the presence of human transferrin
}

\author{
D. A. A. ALA'ALDEEN*, S. P. BORRIELLO* and E. GRIFFITHS $\dagger$
}

Microbial Pathogenicity Research Group, Clinical Research Centre, Watford Road, Harrow, Middlesex HA1 3 UJ and †Department of Bacteriology, National Institute for Biological Standards and Control, Blanche Lane, South Mimms, Potters Bar, Hertfordshire EN6 30 G

\begin{abstract}
Summary. Iron-related tRNA alterations have been shown to occur in several pathogens but nothing has been reported about the effect of iron on meningococcal tRNA. The chromatographic elution profile of ${ }^{3} \mathrm{H}$-tryptophan-tRNA ${ }^{\text {trp }}$ from a Neisseria meningitidis strain grown under different conditions was examined. The profile showed an early (P1) and a late $(\mathrm{P} 2)$ eluting species of $t R N A^{\text {trp }}$, but the proportion of the two species varied under different growth conditions. The elution profile of trp-tRNA ${ }^{\text {trp }}$ from bacteria grown in ironsufficient Mueller Hinton broth yielded a minor P1 species and a major P2 species, whereas under iron-restricted growth induced by desferrioxamine, the pattern was one of a major P1 species and minor P2 species. Iron-restriction induced by human transferrin (HTF) resulted in almost equal amounts of the two tRNA ${ }^{\text {trp }}$ species $(P 1 \bumpeq \mathbf{P} 2)$. Differences in the proportions of the tRNA species were also found between cells grown in liquid medium $(\mathrm{P} 1 \ll \mathrm{P} 2)$ and on the same medium solidified with agar $(\mathrm{P} 1 \gg \mathrm{P} 2)$. The growth phase of the bacteria did not have any effect on the tRNA ${ }^{\text {trp }}$ elution profile. Changes in $\mathrm{TRNA}^{\text {trp }}$ induced by HTF were readily and completely reversible when the cells were transferred to an iron-rich medium, but those induced by desferrioxamine remained irreversible for a long period $(16 \mathrm{~h})$ after such transfer.
\end{abstract}

\section{Introduction}

There is now overwhelming evidence that many crucial virulence determinants of pathogenic bacteria are environmentally regulated and expressed only under certain conditions. ${ }^{1}$ Virulence genes are regulated by various environmental signals including temperature, osmotic pressure, oxygen and the availability of essential nutrients, such as iron. The restricted availability of iron in tissue fluids not only presents microbial pathogens with the problem of acquiring sufficient for multiplication in vivo, but also constitutes a major signal which co-ordinately regulates the expression of a number of virulence and metabolic genes. ${ }^{1.2}$

Much of our understanding of how organisms adjust in vivo to iron limitation comes from studies on Escherichia coli. During iron restriction induced by host iron-binding proteins, E. coli produces siderophores and expresses a number of new outer-membrane proteins. ${ }^{2}$ The expression of many of the iron-

Received 2 Oct. 1992; accepted 16 Nov. 1992.

*Present address and address for correspondence: Microbial Pathogenicity Research Group, Department of Microbiology, Queens Medical Centre, University Hospital, Nottingham NG7 2UH regulated genes is negatively controlled by a global repressor protein (Fur) which uses ferrous iron as a corepressor. ${ }^{3}$ An additional global regulatory system based on under-modification of several transfer ribonucleic acids (tRNAs) also appears to operate. ${ }^{2}$ Iron restriction in $E$. coli produces a family of specifically altered tRNAs. Thus tRNAs for phenylalanine, tyrosine, tryptophan, serine, cysteine and leucine in $E$. coli grown under iron restriction lack the methylthio group $\left(\mathrm{ms}^{2}\right)$ present on the isopentenyl-adenosine $\left(\mathrm{i}^{6} \mathrm{~A}\right)$ located next to the anticodon at position 37 (A37) in tRNA from iron-replete cells. These under-modified forms appear on chromatography as early eluting tRNA species and, on adding iron, ${ }^{4}$ are converted rapidly $(40 \mathrm{~min})$ to the fully modified late-eluting species. The same iron-related tRNA alteration has been shown to occur also in $E$. coli recovered directly from the peritoneal cavities of infected animals. ${ }^{5}$ Under-modification of the nucleotide at A37 in tRNA induces strong pleiotropic effects on cell physiology; in some instances by affecting the translational efficiency of the tRNA, in others by altering codon context effects, and in others by yet unknown mechanisms. ${ }^{6-12}$ This modification may also lead to an increase in the frequency of spontaneous mutations when cells need to adapt to environmental stress. ${ }^{13,14}$ 


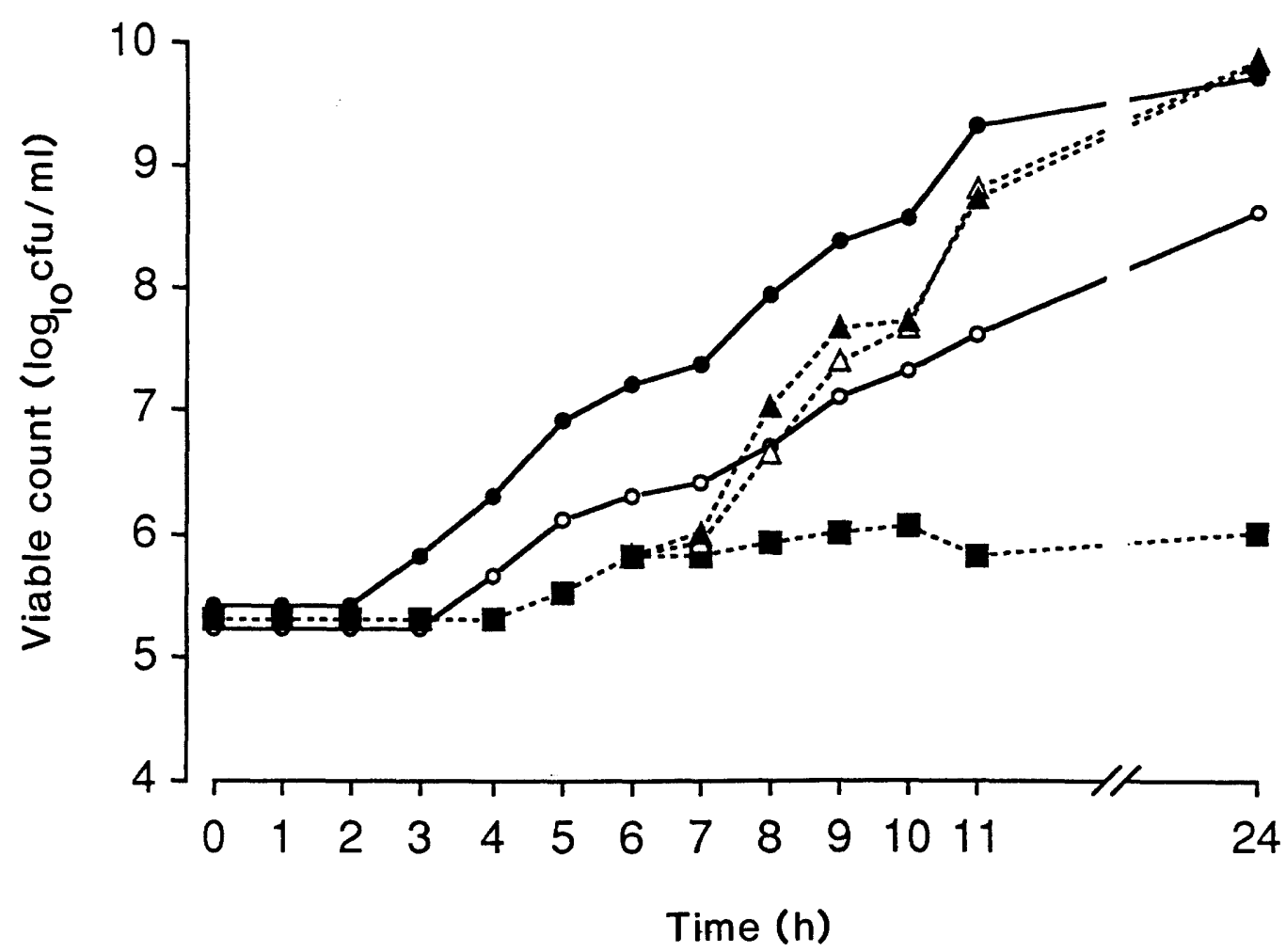

Fig. 1. Growth of $N$. meningitidis strain SD (B15 P1.16) under different conditions: MHB (๑); MHB-TF (O); MHB-D ( $)$ ); transferred from MHB-D at $6 \mathrm{~h}$ to MHB-D with added ferric di-citrate $(\Delta)$, or to fresh MHB $(\triangle)$.

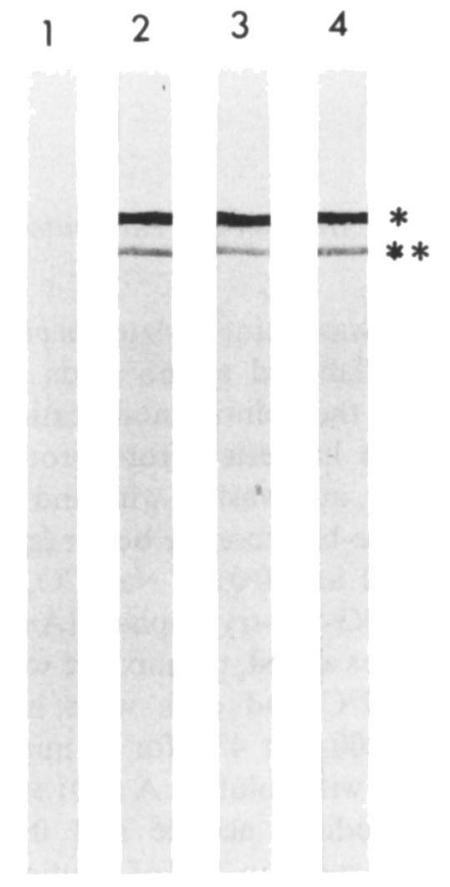

Fig. 2. Western blot of total outer-membrane proteins of $N$ meningitidis strain SD, (B15 P1.16) grown in: 1, MHB; 2, MHB-D 3, MHB-TF for $24 \mathrm{~h} ; 4$, in MHB-TF for $6 \mathrm{~h}$. All membranes were exposed to HRP-HTF overnight and developed before probing with rabbit anti-FrpB (AR-70) antiserum. FrpB was then visualised with peroxidase conjugated goat anti-rabbit (BioRad); *TBP-2, ${ }^{* *}$ FrpB.

Although much less is known about the molecular mechanisms of iron regulation in other organisms, furlike systems have been found in pathogens such as Vibrio cholerae, ${ }^{15}$ Corynebacterium diphtheria $e^{16}$ and
Yersinia pestis, ${ }^{17}$ and tRNA changes have been seen in Salmonella typhimurium, Klebsiella pneumoniae and Pseudomonas aeruginosa when grown in the presence of an iron-binding protein. ${ }^{18}$ It is already known that Neisseria meningitidis expresses several new outermembrane proteins during growth under iron limitation. Some of these proteins are believed to be important for virulence and might be useful protective antigens. ${ }^{19-21}$ Nothing has been reported about the effect of iron restriction on meningococcal tRNA. In the work reported here, the effect of different growth conditions on the chromatographic behaviour of tRNA from $N$. meningitidis was examined.

\section{Materials and methods}

\section{Bacterial growth conditions}

N. meningitidis strain SD (B15 P1.16), also called strain $70942,{ }^{22}$ was grown in Mueller Hinton Broth (MHB) or on Mueller Hinton Agar (MHA) (Oxoid). For iron limitation, desferrioxamine (Ciba) was added to the broth or agar to $25 \mu \mathrm{M}$, yielding MHB-D and MHA-D respectively, as described previously..$^{19,23}$ Broth cultures were incubated overnight at $37^{\circ} \mathrm{C}$ in $\mathrm{CO}_{2} 5 \%$ in flasks with shaking at $80 \mathrm{rpm}$. In some experiments, bacteria were grown overnight in MHB or MHB-D, collected by centrifugation at $1200 \mathrm{~g}$, transferred to fresh MHB or MHB-D, and incubated for a further period.

Other iron chelators used in broth cultures were 


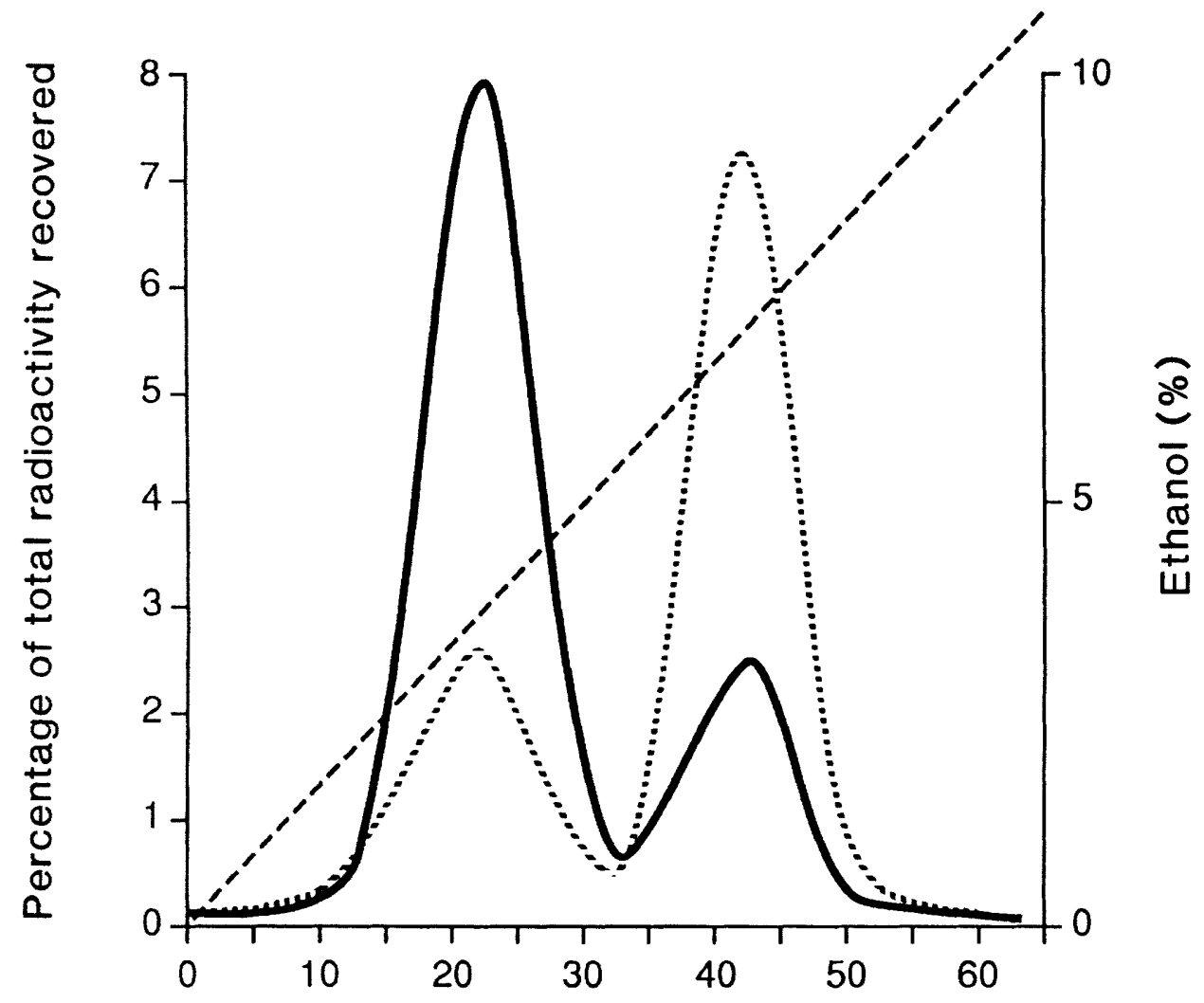

Fraction no.

Fig. 3. BD-cellulose chromatography of $\left[{ }^{3} \mathrm{H}\right]$-trp-tRNA ${ }^{\text {trp }}$ extracted from N. meningitidis strain SD (B15 P1.16) grown in MHB (....) and in MHB-D ( - following overnight incubation. Ethanol gradient (-..----).

ethylenediaminedihydroxyphenylacetic acid (EDDA, Sigma) $14 \mu \mathrm{g} / \mathrm{ml}$, yielding MHB-E, and human transferrin (HTF, Sigma) $1 \mathrm{mg} / \mathrm{ml}$, dissolved in $\mathrm{NaHCO}_{3}$ $0.6 \%$ before adding to MHB, yielding MHB-TF. Ferric di-citrate, prepared as described previously, ${ }^{24}$ was used as an iron supplement at concentrations (v/v) of $0.5 \%$ for MHB and MHA and $1 \%$ for MHB$\mathrm{D}$ and MHA-D.

\section{Comparative growth curve}

MHB, MHB-D and MHB-TF were inoculated with an overnight static phase MHB culture of strain SD to give $10^{5} \mathrm{cfu} / \mathrm{ml}$ and incubated with shaking as above. The viable count of the cultures was determined every hour by the micro-assay procedure described previously. ${ }^{25}$ After $6 \mathrm{~h}$, the MHB-D culture was divided into three equal volumes: one volume was re-incubated without change; another was supplemented with ferric di-citrate $1 \% \mathrm{v} / \mathrm{v}$ before re-incubation; and the third volume was centrifuged at $1200 \mathrm{~g}$ for $20 \mathrm{~min}$ at $4^{\circ} \mathrm{C}$ and the harvested cells were resuspended in fresh MHB and then re-incubated. While this sample was being centrifuged, all the other samples were removed from the incubator and stored temporarily at $4^{\circ} \mathrm{C}$ before re-incubation at $37^{\circ} \mathrm{C}$.
Aminoacylation, extraction and chromatography of aminoacyl-tRNA

Transfer RNA was aminoacylated in vivo with a 10min pulse of ${ }^{3} \mathrm{H}$-labelled amino acids as described previously ${ }^{4}$ with the minor modifications detailed below. Cells were harvested from broth by centrifugation at $1200 \mathrm{~g}$, and washed with and resuspended in $10 \mathrm{ml}$ of glucose-bicarbonate buffer (glucose $0.1 \%$ $\mathrm{w} / \mathrm{v}, 0.15 \mathrm{M} \mathrm{NaCl}$ and $0.01 \mathrm{M} \mathrm{NaHCO}_{3}, \mathrm{pH} 7.6$ ) at $37^{\circ} \mathrm{C} ; 100 \mu \mathrm{Ci} \mathrm{L}-\left[\mathrm{G}-{ }^{3} \mathrm{H}\right]$-tryptophan (Amersham International plc) was added, the mixture was incubated for $10 \mathrm{~min}$ at $37^{\circ} \mathrm{C}$ and cells were harvested by centrifugation $\left(1200 \mathrm{~g}\right.$ at $4^{\circ} \mathrm{C}$ for $\left.30 \mathrm{~min}\right)$. The cells were washed once with solution $\mathrm{A}(0.01 \mathrm{M}$ magnesium acetate, $0.05 \mathrm{M}$ sodium acetate and $0.15 \mathrm{M} \mathrm{NaCl}$, $\mathrm{pH} \mathrm{4.5)} \mathrm{and} \mathrm{resuspended} \mathrm{in} 2 \mathrm{ml}$ of solution A. Carrier cells (1-2 g of E. coli strain O111) were mixed with the labelled cells and the volume was made up to $10 \mathrm{ml}$ with solution A. An equal volume of phenol $80 \% \mathrm{w} / \mathrm{v}$ was added to the cell suspension and the mixture was shaken at $4^{\circ} \mathrm{C}$ for $20 \mathrm{~min}$. The aminoacyl-tRNA was precipitated from the aqueous phase by potassium acetate (pH 4.5, 20\% w/v) and ethanol and reprecipitated from solution $\mathrm{B}(0.01 \mathrm{M}$ magnesium acetate, $0.05 \mathrm{~m}$ sodium acetate and $1 \mathrm{M} \mathrm{NaCl}, \mathrm{pH} 4.5$ ); the 
final ethanol precipitate was dissolved in $5 \mathrm{ml}$ of solution A for chromatography.

A benzoylated DEAE-cellulose (BD-cellulose, Cellex-BD, BioRad) column was packed as described before $^{4}$ and equilibrated with solution B. After the addition of $10 \mathrm{ml}$ of solution $A$, the aminoacyl-tRNA preparation was applied. The column was washed with $100 \mathrm{ml}$ of solution B (flow rate $0.5 \mathrm{ml} / \mathrm{min}$ ) and bound aminoacyl-tRNA was eluted with a linear gradient of ethanol $(0-20 \% \mathrm{v} / \mathrm{v})$ in solution $\mathrm{B}$; 5 -ml fractions were collected and the radioactivity present was measured as described previously. ${ }^{4}$ Elution profiles were obtained by plotting the amount of radioactivity found in each fraction, expressed as a percentage of the total radioactivity recovered, versus the fraction number.

\section{Extraction of outer-membrane proteins (OMPs), SDS-PAGE and Western blotting}

OMPs were extracted from $N$. meningitidis strain SD, separated by SDS-PAGE and Western blotted as described previously. ${ }^{19,23}$ Polyclonal monospecific antibodies (AR-70) against the $70-\mathrm{kDa}$ iron-regulated protein of meningococci (now referred to as FrpB) were raised, and used in Western blots as described previously. ${ }^{23}$ Horseradish peroxidase-labelled HTF (HRP-HTF) was also used as described ${ }^{26}$ to visualise transferrin binding protein, TBP-2 on Western blots.

\section{Results}

\section{Growth of N. meningitidis under different conditions}

The effects of various iron chelators on the growth of $N$. meningitidis in MHB are shown in fig. 1. The bacteria remained in a lag phase for $2 \mathrm{~h}$ in MHB, $3 \mathrm{~h}$ in MHB-TF and $4 \mathrm{~h}$ in MHB-D before exponential growth started. The exponential growth rate in MHBTF was slightly slower than that in MHB and was extremely slow in the desferrioxamine-containing medium (MHB-D). The expression of the iron-regulated $70-\mathrm{kDa}$ protein (FrpB) and the HTF-binding protein TBP-2 by $N$. meningitidis strain SD when grown in MHB-D and MHB-TF confirmed that the organisms were growing under nutritional stress (fig. 2). These proteins were not expressed when the strain was grown in MHB or on MHA.

The deleterious effect of desferrioxamine on growth rate was swiftly and almost completely reversed as soon as ferric di-citrate was added to the medium or the cells were transferred to fresh MHB. Meningococci did not grow well in the presence of EDDA (MHB-E) although they expressed the iron regulated proteins.

\section{Alteration in $t R N A^{\text {trp }}$ profiles induced by various growth conditions}

The chromatographic elution profile of ${ }^{3} \mathrm{H}$-trp-
tRNA $^{\text {trp }}$ from overnight MHB cultures of $N$. meningitidis is shown in fig. $3 ; c .23 \%$ of the tRNA ${ }^{\text {trp }}$ eluted between $2 \%$ and $5.5 \%$ ethanol, yielding a minor species peak (P1) and was followed by a major species peak (P2) (71\%) eluting between $5.5 \%$ and $8.5 \%$ ethanol. This pattern of a minor P1 followed by major $\mathrm{P} 2$ was reproducible in repeat experiments and was the same whether or not the cells were in the lag, exponential or stationary phase of growth at the time of tRNA extraction. In contrast, chromatographic analysis of tRNA ${ }^{\text {trp }}$ from cells grown overnight in MHB-D produced an elution profile which was essentially the reverse of that produced under ironsufficient conditions, with a major species $(72 \%)$ peak eluting early at the $\mathrm{P} 1$ position and a minor species $(21 \%)$ peak late at the $\mathrm{P} 2$ position. The switch from a

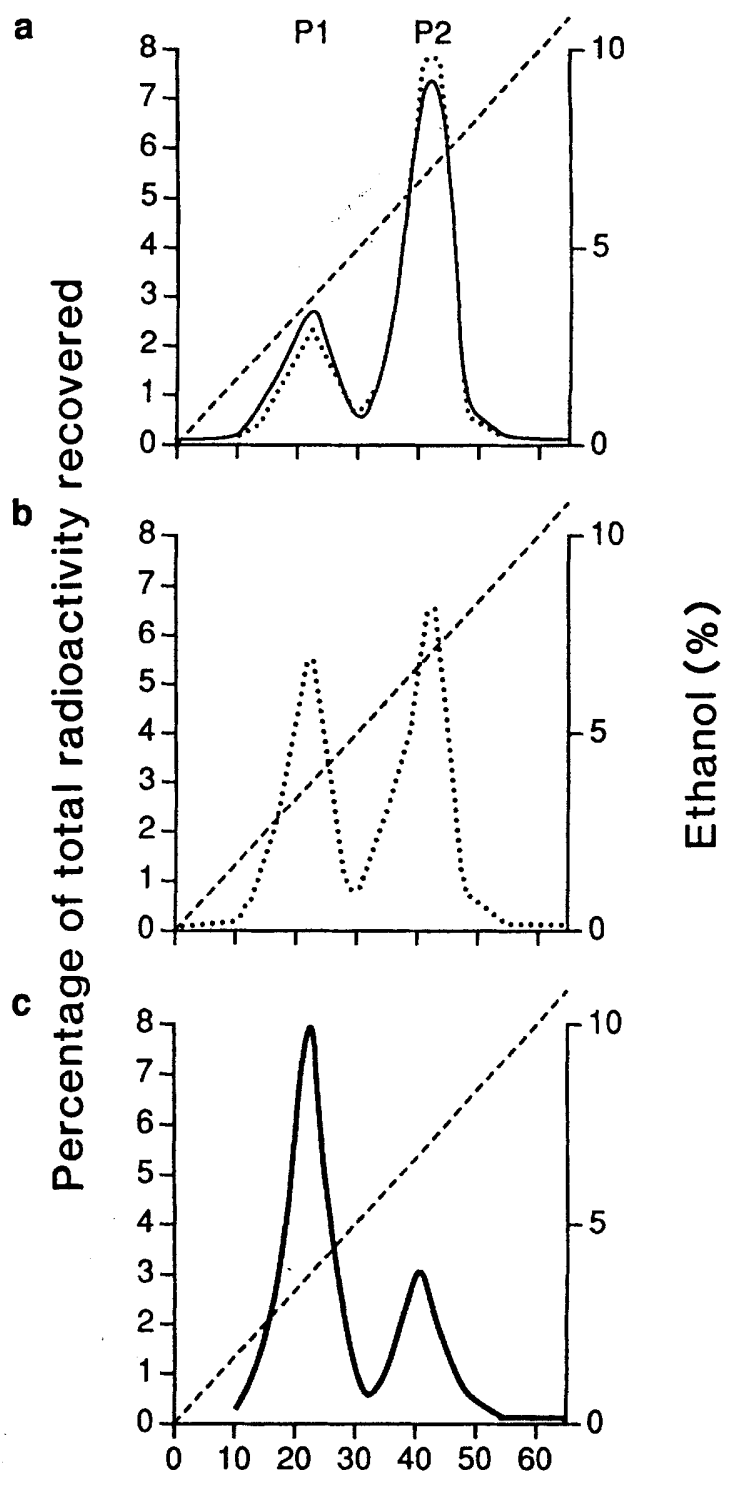

\section{Fraction no.}

Fig. 4. BD-cellulose chromatography of $\left[{ }^{3} \mathrm{H}\right] \operatorname{trp}-\mathrm{tRNA}{ }^{\text {trp }}$ extracted from $N$. meningitidis strain SD grown in MHB overnight and then transferred into fresh a, MHB for $3 \mathrm{~h} \mathrm{(-)}$ and MHB-D for $3 \mathrm{~h}$ $(\ldots .$.$) ; b, MHB-D for 6 \mathrm{~h}$; c, MHB-D for $16 \mathrm{~h}$. Ethanol gradient $(---)$. $\mathrm{P} 1$ and $\mathrm{P} 2=$ peaks 1 and 2 . 


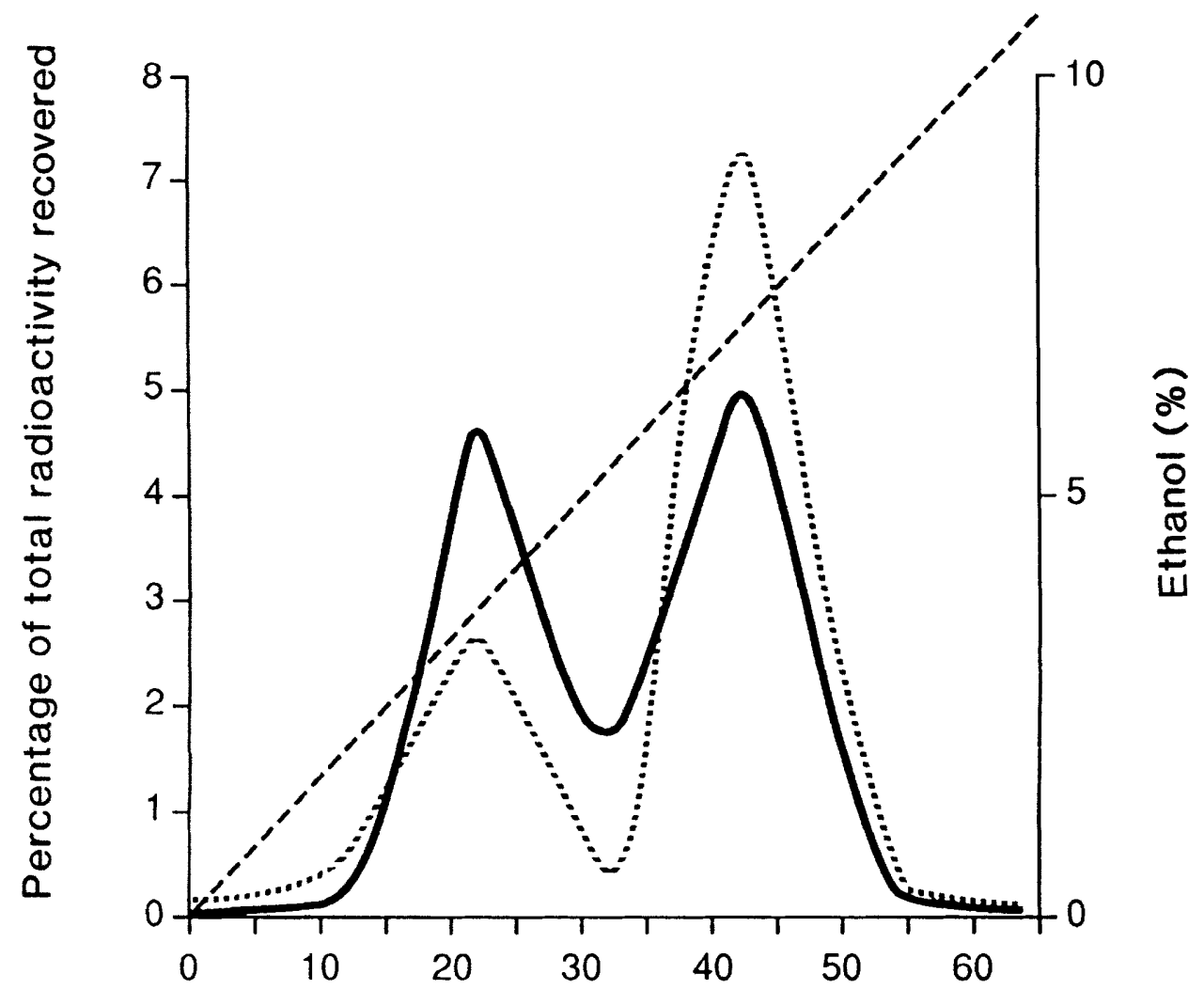

Fraction no.

Fig. 5. BD-cellulose chromatography of $\left[{ }^{3} \mathrm{H}\right] \mathrm{trp}-\mathrm{RNA}{ }^{\text {trp }}$ extracted from $N$. meningitidis strain $\mathrm{SD}$ grown in MHB-TF for $24 \mathrm{~h}$ before $(\ldots \ldots \ldots)$ and $6 \mathrm{~h}$ after $(-\ldots)$ adding ferric di-citrate to the medium. Elution gradient (---.-).

P2-dominant tRNA species pattern for MHB cultures to the P1-dominant tRNA species one for MHB-D cultures occurred slowly. Growth in MHB-D for up to $3 \mathrm{~h}$ showed no change, but at $6 \mathrm{~h}$ small but significant changes in the relative proportions of $\mathrm{P} 1$ and $\mathrm{P} 2$ were seen and the process was complete by $16 \mathrm{~h}$ (fig. 4).

When HTF was used to chelate the available iron in MHB, approximately equal amounts of tRNA in peaks P1 $(46 \%)$ and P2 (48\%) were obtained after overnight growth of the organisms (fig. 5). This profile was independent of the growth phase of the bacteria.

As it is known that in $E$. coli the early eluting tRNA species is a precursor of the late eluting one, it was important to see whether the P1 tRNA species was in any way related to the $P 2$. Results showed that $6 \mathrm{~h}$ after transferring $N$. meningitidis grown in MHB-D to the iron-rich MHB (with added ferric di-citrate) no significant changes to the tRNA elution profile had occurred (fig. 6) despite the fact that the growth rate had recovered almost completely by that time (fig. 1). Even $24 \mathrm{~h}$ after transfer to iron-rich MHB, only partial recovery had been achieved, despite the fact that the bacteria had reached the stationary phase much earlier.

In contrast to that with the cells grown with desferrioxamine, within $6 \mathrm{~h}$ of adding sufficient iron to MHB-TF to oversaturate the iron-binding capacity of the HTF, the tRNA ${ }^{\text {trp }}$ elution profile had returned to that with a minor P1 (22\%) and major P2 (72\%) peak (fig. 5).

\section{Effects of other growth conditions}

To determine whether any of the changes in tRNA ${ }^{\text {trp }}$ shown above could also be induced by other growth conditions, the $N$. meningitidis strain was grown overnight on the same medium solidified with agar (MHA) before the extraction of tRNA. The results showed that the chromatographic profile of trptRNA $^{\text {trp }}$ from the organism grown on MHA was very similar to that produced when grown in MHB-D (see fig. 3). To see whether the alteration of the trp-tRNA profile from that given by cultures grown in MHB was due to lack of access to free iron or to the change in the growth environment from liquid to solid, ferric dicitrate $(1 \%)$ was added to the MHA. This made no difference, and the major P1 and minor P2 tRNA pattern was again obtained. The incorporation of desferrioxamine into MHA (MHA-D) further suppressed the P2 tRNA species.

\section{Discussion}

The results show that changes occur in the tRNA ${ }^{\text {trp }}$ of $N$. meningitidis grown under iron-restricted conditions. However, it is important to note that the 


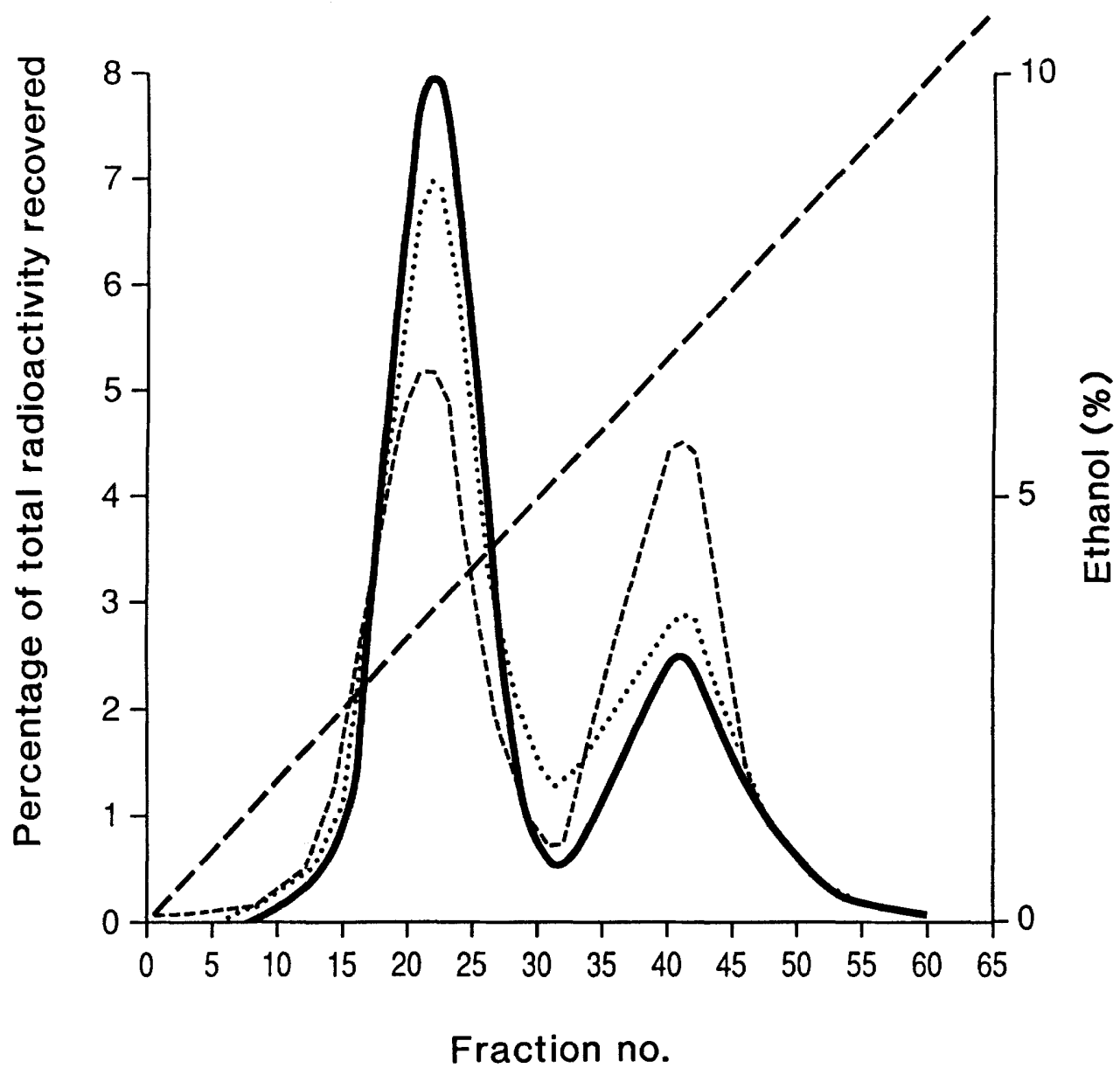

Fig. 6. BD-cellulose chromatography of $\left[{ }^{3} \mathrm{H}\right] \operatorname{trp}-\mathrm{tRNA}{ }^{\text {trp }}$ extracted from $N$. meningitidis strain SD grown in MHB-D overnight ( $\longrightarrow$ ) and then transferred into fresh MHB containing ferric di-citrate and incubated for $6 \mathrm{~h}(\ldots \ldots \ldots)$ and $\left.24 \mathrm{~h}(---)^{--}\right)$. Elution gradient (---).

response to iron restriction by desferrioxamine and that produced by the presence of HTF in the medium was different; only the change produced by HTF seemed readily reversible and likely to reflect ironrelated tRNA modification as seen in $E$. coli. Thus, the two systems are not identical and the use of desferrioxamine, although convenient, may not entirely mimic the more naturally produced iron-restricted environment imposed by the iron-binding protein. We suggest that desferrioxamine, an iron-chelator used widely experimentally, ${ }^{19,23,27}$ creates an artificial environment for the organisms where iron may be completely unavailable to the cells or where other trace elements, e.g., aluminium, copper, zinc and magnesium,${ }^{28}$ may also be limiting. Such stressful growth conditions could result in both general and specific effects on the formation of modified bases in tRNA, resulting in molecules that may be incapable of being converted to the normal species. Similar effects are seen when $E$. coli is cultured under stressful conditions, such as growth in the presence of chloramphenicol or in the absence of methionine, leucine or cysteine, which lead to the uncoupling of RNA and protein synthesis. The abnormal $E$. coli tRNA species that accumulate under such conditions, though chromatographically similar to those found in iron-restricted $E$. coli, are only converted to the normal species very slowly, or not at all, on restoration of normal growth. ${ }^{29-33}$ Such abnormal tRNAs have a number of modified nucleosides missing as well as the methylthio-moiety of $\mathrm{ms}^{2} \mathrm{i}^{6} \mathrm{~A}$. However, it is also possible that two different and unrelated species of tRNA ${ }^{\text {trp }}$ exist in $N$. meningitidis and that one or other is preferentially expressed during these different growth conditions.

Our results show that $N$. meningitidis grown in a liquid medium is phenotypically different from that grown on solid medium. Although MHA has been reported to be relatively iron limited compared to $\mathrm{MHB}^{34}$, in this case the tRNA changes seem not to be related to the lack of iron, although again it is not known if the chromatographically similar iso-accepting tRNA species seen are identical to those found during iron restriction.

A detailed analysis of the early and late eluting tRNA ${ }^{\text {trp }}$ species is now required to understand the molecular relationship between them and to see if iron restriction itself, as induced by HTF, results in the failure to methylthiolate an isopentenyladenosine in these tRNAs. Preliminary data (unpublished results) show that changes similar to those seen with tRNA ${ }^{\text {trp }}$ also occur in meningococcal phenylalanine and tyrosine tRNA under the same growth conditions. It remains to be seen whether any of these changes are connected with the adaptation of $N$. meningitidis to 
growth in an iron-restricted environment, as appears to be the case in $E$. coli.

\section{References}

1. Griffiths E. Environmental regulation of bacterial virulenceimplications for vaccine design and production. Trends Biotechnol. 1991; 9: 309-315.

2. Griffiths E. Iron and bacterial virulence--a brief overview. Biol Met 1991; 4: 7-13.

3. Bagg A, Neilands JB. Molecular mechanisms of regulation of siderophore-mediated iron assimilation. Microbiol Rev $1987 ; 51: 509-518$

4. Griffiths E, Humphreys J. Alterations in tRNAs containing 2 methylthio- $N^{6}\left(\Delta^{2}\right.$-isopentenyl)-adenosine during growth of enteropathogenic Escherichia coli in the presence of iron-binding proteins. Eur $J$ Biochem $1978 ; 82$ : 503-513.

5. Griffiths E, Humphreys J, Leach A, Scanlon L. Alterations in the tRNA's of Escherichia coli recovered from lethally infected animals. Infect Immun 1978: 22: 312-317.

6. Buck M, Griffiths E. Regulation of aromatic amino acid transport by tRNA: role of 2 -methylthio- $\mathrm{N}^{6}-\left(\Delta^{2}\right.$-isopentenyl)-adenosine. Nucleic Acids Res 1981;9:401-414.

7. Buck M, Griffiths E. Iron mediated methylthiolation of tRNA as a regulator of operon expression in Escherichia coli. Nucleic Acids Res 1982; 10: 2609-2624.

8. Ericson JU, Bjork GR. Pleiotropic effects induced by modification deficiency next to the anticodon of tRNA from Salmonella typhimurium LT2. J Bacteriol 1986; 166 1013-1021.

9. Ericson JU, Bjork GR. tRNA anticodons with the modified nucleosides 2-methylthio- $\mathrm{N}^{6}$ (4-hydroxyisopentenyl) adenosine distinguish between bases $3^{\prime}$ of the codon. $J \mathrm{Mo}$ Biol 1991; 218 : 509-516.

10. Bouadloun F, Srichaiyo T, Isaksson LA, Bjork GR. Influence of modification next to the anticodon in tRNA on codon context sensitivity of translational suppression and accuracy. J Bacteriol 1986; 166: 1022-1027.

11. Wilson RK, Roe BA. Presence of the hypermodified nucleotide N-6-(delta-2-isopentenyl)-2-methylthioadenosine prevents codon misreading by Escherichia coli phenylalanyl-transfer-RNA. Proc Nall Acad Sci USA 1989; 86: 409-413.

12. Petrullo LA, Elseviers D. Effect of a 2-methylthio- $\mathbf{N}^{6}$-isopentenyladenosine deficiency on peptidyl-tRNA release in Escherichia coli. J Bacteriol 1986; 65: 608-611.

13. Connolly DM, Winkler ME. Genetic and physiological relationships among the miaA gene, 2-methylthio- $\mathrm{N}^{6}$-(delta-2 isopentenyl)-adenosine tRNA modification and spontaneous mutagenesis in Escherichia coli K-12. J Bacteriol 1989; 171: 3233-3246.

14. Connolly DM, Winkler ME. Structure of Escherichia coli K-12 miaA and characterization of the mutator phenotype caused by miaA insertion mutations. J Bacteriol $1991 ; 173$ : 1711-1721.

15. Goldberg MB, Dirita VJ, Calderwood SB. Identification of an iron-regulated virulence determinant in Vibrio cholerae, using TnphoA mutagenesis. Infect Immun 1990; 58: 55-60.

16. Fourel G, Phalipon A, Kaczorek M. Evidence for direct regulation of diphtheria toxin gene transcription by an $\mathrm{Fe}^{2+}$-dependent DNA-binding repressor Dtox $\mathbf{R}$, in Corynebacterium diphtheriae. Infect Immun 1989; 57: 3221-3225.

17. Staggs TM, Perry RD. Identification and cloning of a fur regulatory gene in Yersinia pestis. $J$ Bacteriol 1991; 173 : $417-425$.
We thank Miss Pauline Stevenson for her assistance. D.A.A thanks the Sir Halley Stewart Trust for financial support.
18. McLennan BD, Buck M, Humphreys J, Griffiths E. Iron related modification of bacterial RNA. Nucleic Acids Res 1981; 9 2629-2640

19. Ala'Aldeen DA, Wall RA, Borriello SP. Immunogenicity and cross-reactivity of the $70-\mathrm{kDa}$ iron-regulated protein of Neisseria meningitidis in man and animals. $J$ Med Microbiol 1990; 32: 275-281.

20. Black JR, Dyer DW, Thompson MR, Sparling PF. Human immune response to iron-repressible outer membrane proteins of Neisseria meningitidis. Infect Immun 1986; 54 $710-713$

21. Banerjee-Bhatnagar N, Frasch CE. Expression of Neisseria meningitidis iron-regulated outer membrane proteins, including a 70-kilodalton transferrin receptor, and their potential for use as vaccine. Infect Immun 1990; 58 2875-2881

22. Griffiths E, Stevenson P, Ray A. Antigenic and molecular heterogeneity of the transferrin-binding protein of Neisseria meningitidis. FEMS Microbiol Lett 1990; 57: 31-36

23. Ala'Aldeen DA, Davies HA, Wall RA, Borriello SP. The 70 kilodalton iron regulated protein of Neisseria meningitidis is not the human transferrin receptor. FEMS Microbiol Lett $1990 ; 57: 37-42$

24. Bates GW, Billups C, Saltman P. The kinetics and mechanisms of iron(III) exchange between chelates and transferrin. $J$ Biol Chem 1967; 242: 2810-2815.

25. Borriello SP, Barclay FE. An in-vitro model of colonisation resistance to Clostridium difficile infection. $J$ Med Microbio 1986; 21 : 299-309.

26. Schryvers AB, Morris LJ. Identification and characterisation of the transferrin receptor from Neisseria meningitidis. Mol Microbiol 1988; 2: 281-288.

27. Bullen JJ, Griffiths E. Iron and infection: molecular, physiological and clinical aspects. Chichester, John Wiley and Sons. 1987.

28. Ackrill P Day JP. Desferrioxamine in the treatment of aluminium overload. Clin Nephrol 1985; 24 Suppl 1 S94-S97.

29. Mann MB, Huang P. Behavior of chloramphenicol-induced phenylalanine transfer ribonucleic acid during recovery from chloramphenicol treatment in Escherichia coli. Biochemistry 1973 ; 12: 5289-5294.

30. Juarez H, Skjold AC, Hedgcoth C. Precursor relationship of phenylalanine transfer ribonucleic acid from Escherichia coli treated with chloramphenicol or starved for iron, methionine or cysteine. $J$ Bacteriol $1975 ; 121: 44-54$.

31. Kitchingman GR, Fournier MJ. Unbalanced growth and the production of unique transfer ribonucleic acids in relaxedcontrol Escherichia coli. J Bacteriol 1975; 124: 1382-1394.

32. Kitchingman GR, Fournier MJ. Modification-deficient transfer ribonucleic acids from relaxed control Escherichia coli. structures of the major undermodified phenylalanine and leucine transfer RNAs produced during leucine starvation. Biochemistry 1977; 16: 2213-2220.

33. Kitchingman GR, Webb E, Fournier MJ. Unique phenylalanine transfer ribonucleic acid in relaxed control of Escherichia coli: Genetic origin and some functional properties. Biochemistry 1976; 15: 1848-1857.

34. Critchley IA, Basker MJ. Conventional laboratory agar media provide an iron limited environment for bacterial growth. FEMS Microbiol Lett 1988; 50: 35-39. 